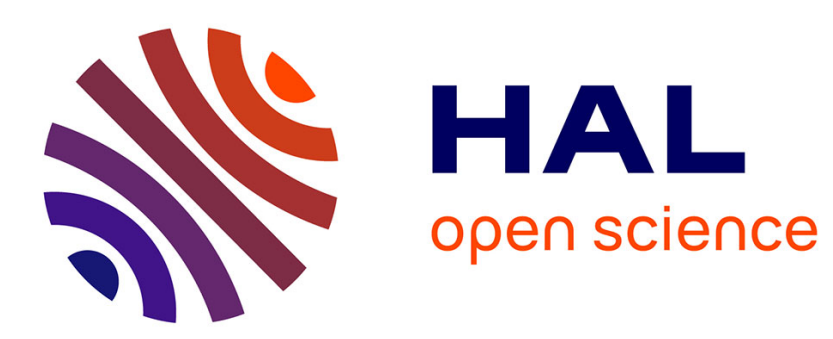

\title{
A new ultrasonic fatigue testing device for biaxial bending in the gigacycle regime
}

Charles Brugger, Thierry Palin-Luc, Pierre Osmond, Michel Blanc

\section{To cite this version:}

Charles Brugger, Thierry Palin-Luc, Pierre Osmond, Michel Blanc. A new ultrasonic fatigue testing device for biaxial bending in the gigacycle regime. International Journal of Fatigue, 2017, 10.1016/j.ijfatigue.2016.12.039 . hal-01468535

\section{HAL Id: hal-01468535 \\ https://hal.science/hal-01468535}

Submitted on 15 Feb 2017

HAL is a multi-disciplinary open access archive for the deposit and dissemination of scientific research documents, whether they are published or not. The documents may come from teaching and research institutions in France or abroad, or from public or private research centers.
L'archive ouverte pluridisciplinaire $\mathbf{H A L}$, est destinée au dépôt et à la diffusion de documents scientifiques de niveau recherche, publiés ou non, émanant des établissements d'enseignement et de recherche français ou étrangers, des laboratoires publics ou privés. 


\title{
A new ultrasonic fatigue testing device for biaxial bending in the gigacycle regime
}

\author{
C. Brugger ${ }^{\mathrm{a}, *}$, T. Palin-Luc ${ }^{\mathrm{a}}$, P. Osmond ${ }^{\mathrm{b}}$, M. Blanc ${ }^{\mathrm{b}}$ \\ a Arts et Metiers ParisTech, I2M, CNRS, Universite de Bordeaux, Esplanade des Arts et Metiers, 33405 Talence Cedex, France \\ ${ }^{\mathrm{b}}$ PSA Peugeot Citroën, 18 rue des fauvelles, 92256 La Garenne-Colombes Cedex, France
}

Keywords:

Very high cycle fatigue

Biaxial stress

Cast metal

Aluminum alloy

Experimental technique

\begin{abstract}
A B S T R A C T
A new fatigue testing device has been developed to test specimens under biaxial loading at $20 \mathrm{kHz}$. The specimen is a flat smooth disc. It is placed on a torus frame and cyclically loaded in compression at the center of its upper face. Consequently disc bending generates a biaxial proportional stress state at the center of the specimen lower face. Any positive loading ratio can be applied. This device has been tested and is well functioning on specimens made of a cast aluminum alloy used to produce cylinder heads. Preliminary results in VHCF regime are compared with literature results obtained under similar stress state but in HCF regime and at $20 \mathrm{~Hz}$ only.
\end{abstract}

\section{Introduction}

Many components in several industries are loaded in very high cycle fatigue (VHCF) regime, either at high frequency (wheels of high speed trains, blades in aircraft turbojet engines, etc.) [1] or at low frequency during decades (artificial heart, mooring chains for off-shore petroleum platforms, etc.) [2,3]. Testing specimens up to $10^{9}$ or $10^{10}$ cycles in a realistic time requires to use a very high loading frequency (20 or $30 \mathrm{kHz}$ ). Several devices using the ultrasonic testing technique have been developed all over the world since Mason's work in the 1950s [4]. A significant effort in this field has been done since the end of the last century $[1,5]$. Specimens can be tested under tension $(R=-1$ or $R>0)$, torsion $(R=-1$ or $R>0)$ or bending $(R>0)$, either at room, low or high temperature, in air or in liquid environment [1-5], but up to very recently there was no machine for testing specimens under multiaxial loading. However, it is known that during their life many industrial components are submitted to multiaxial loadings that may lead to a number of cycles close to one billion or more. Fatigue cracks may initiate in areas experiencing multiaxial stress states. That is the reason why a new fatigue testing device has been developed to test specimens under biaxial loading at $20 \mathrm{kHz}$.

\footnotetext{
* Corresponding author.

E-mail address: charles.brugger@ensam.eu (C. Brugger).
}

After presenting a brief state of the art on ultrasonic fatigue testing machines, the principle of a new biaxial bending device and the associated stress state are presented hereafter. The preliminary results obtained on a cast $\mathrm{Al}-\mathrm{Si}$ alloy in $\mathrm{VHCF}$ regime are then presented and compared with those obtained in literature under similar stress state but in HCF regime and under lower loading frequency.

\section{State of the art: ultrasonic fatigue testing machines}

According to the literature, the first ultrasonic fatigue testing device was developed by Mason in the 1950s under fully reversed tension $[4,6]$. An interesting review of ultrasonic fatigue testing machines is given by Bathias in [5]. The basic principle of an ultrasonic fatigue testing machine is to apply to a specimen an axial sinusoidal displacement at an ultrasonic frequency (typically $20 \mathrm{kHz}$ ). The specimen is designed so that it has a natural frequency (or mode) at this frequency. An ultrasonic fatigue testing machine is made with: (i) a generator applying an electric sinusoidal signal (at $20 \mathrm{kHz}$ ) to (ii) a piezoelectric converter that converts this electric signal in a longitudinal vibration at the same frequency, and (iii) a horn for amplifying the vibration finally applied at one end of the specimen. The generator is controlled by a computer so that the resonance of the whole system (piezo- 
electric converter, horn and specimen) is kept all the test long together with the demanded displacement amplitude.

This principle has been used by several authors to design special apparatuses for testing specimens under fully reversed tension. Coupled with electromechanical or servo-hydraulic testing machines, such equipment can be used for gigacycle fatigue tests under tension with several positive $\mathrm{R}$ ratios. A machine has been developed for three point bending test with $R>0$ too [1]. All these machines allow tests on smooth or notched specimens under uniaxial stress state. Some authors $[1,7,8]$ have also developed torsion testing machines working like uniaxial ones, by pulse and pause $[7,8]$ or continuously [9]. Furthermore, the ultrasonic testing technique can be used for testing specimens at room temperature with air cooling if needed, or at high temperature $[1,10]$, in cryogenic environment [1] or in corrosive liquid environment [2,3]. But these testing machines apply a uniaxial loading on the specimen.

Vieira, De Freitas et al. [11] recently presented a horn and specimen design allowing for fully reversed proportional tensiontorsion ultrasonic testing. For a given load ratio, diagonal hollows are machined in the horn, so that it turns a longitudinal vibration into a coupled longitudinal and torsional one. In this case, the specimen has a triple hourglass geometry, so that the first natural frequency for tension matches the third one for torsion. Only the central neck of the specimen is submitted to both tension and torsion.

\section{New ultrasonic biaxial bending device}

\subsection{Principle}

The new fatigue testing device presented hereafter is designed for testing in bending under ultrasonic loading frequency a flat smooth specimen with a disc geometry [12]. Its principle is similar to the testing apparatus proposed by Koutiri et al. $[13,14]$ but this last one was mounted on a servo-hydraulic testing machine working around $20 \mathrm{~Hz}$ only. The specimen is placed on a frame with a torus ring, so that the contact zone between the lower face of the disc and the frame is a circle. A compressive loading is applied at the center of the upper face using a hemispherical indenter (Fig. 1a). Like in a three point bending test, this leads to the bending of the disc.

Using an electromechanical testing machine and an ultrasonic loading device, both a static load and a sinusoidal displacement (at $20 \mathrm{kHz}$ ) are applied at the center of the specimen. Under the common assumption that the material remains macroscopically elastic in gigacycle fatigue regime, any positive loading ratio can be applied. In practice, to assure uninterrupted contact between specimen and indenter, loading ratios very close to zero are avoided; $\mathrm{R}>0.05$ is recommended.

The ultrasonic loading device, partly illustrated in Fig. 1b, is classic [1]. It consists of a $20 \mathrm{kHz}$ electric generator, a piezoelectric converter, a booster and a horn to amplify the sinusoidal axial displacement like in 3 point ultrasonic bending [1,5]. In order to apply a non-zero mean load, this device is attached to an electromechanical testing machine using bars and hollowed discs fastened to the center of the booster, which is a vibration node. Finally, a servocontrol system adjusts in real time both the amplitude of displacement and the loading frequency to match the natural frequency of the whole device. For that reason, each part (booster, horn and specimen) must be carefully designed, so that their natural frequency for axial displacement matches $20 \mathrm{kHz}$. The next section details, for some components, how their geometry was determined by modal analysis with finite element analysis software.

\subsection{Geometry of the specimen and device}

First, in order to perform a modal analysis, both the density and the dynamic modulus (at $20 \mathrm{kHz}$ ) of the tested material are experimentally measured by using a cylindrical bar as explained in [1] for designing tension-compression specimens. The specimen geometry (Fig. 2a) is described by only two parameters: diameter and thickness of the disc. These parameters are determined iteratively using a free-free modal analysis computed with a commercial FEA software. The ideal geometry corresponds to a first natural frequency - associated with biaxial bending (Fig. 2b) equal to $20 \mathrm{kHz}$. Additionally, other natural modes have to be far

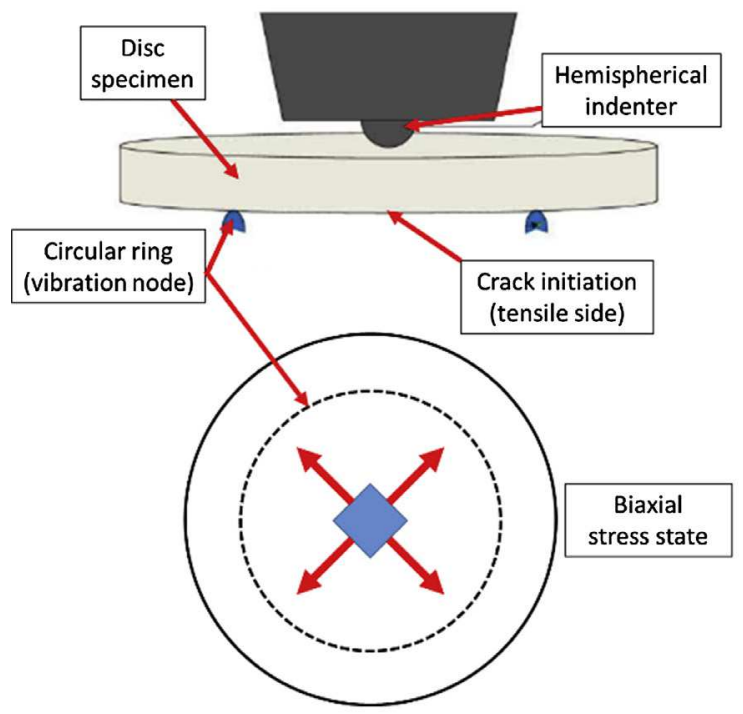

(a)

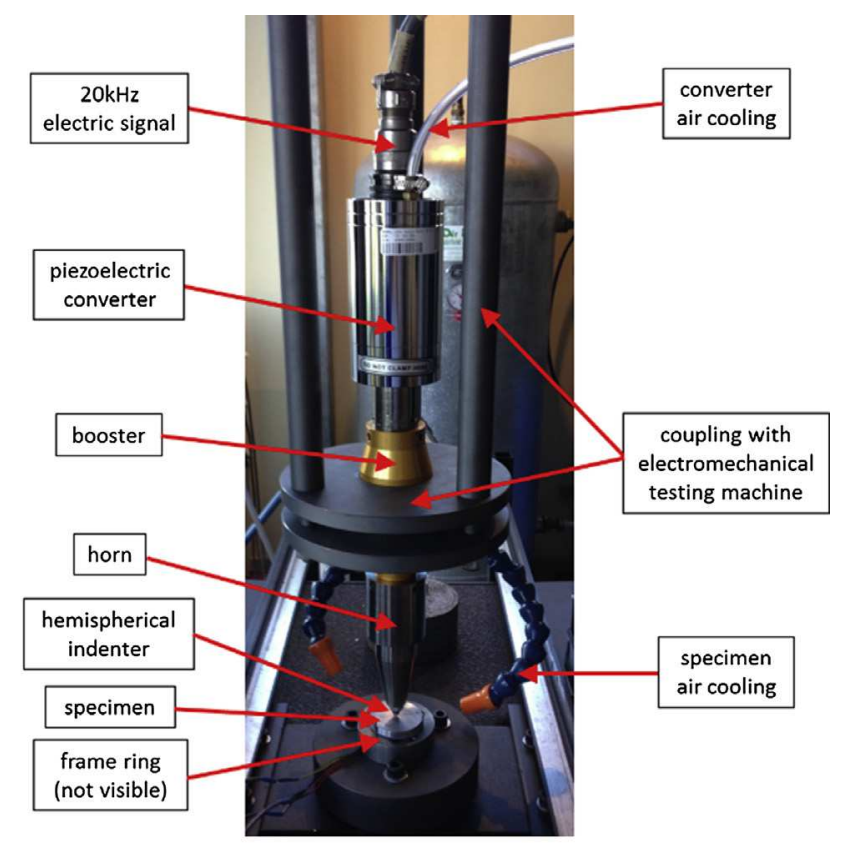

(b) 


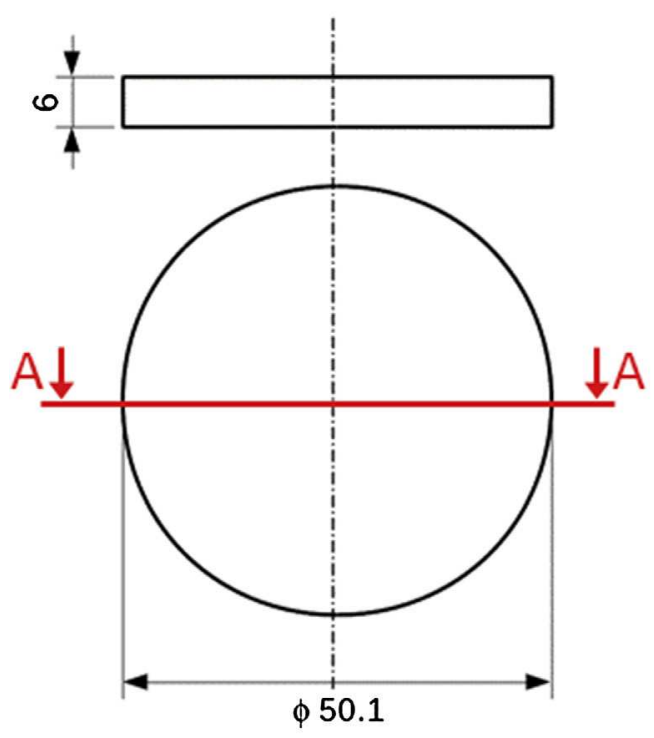

(a)
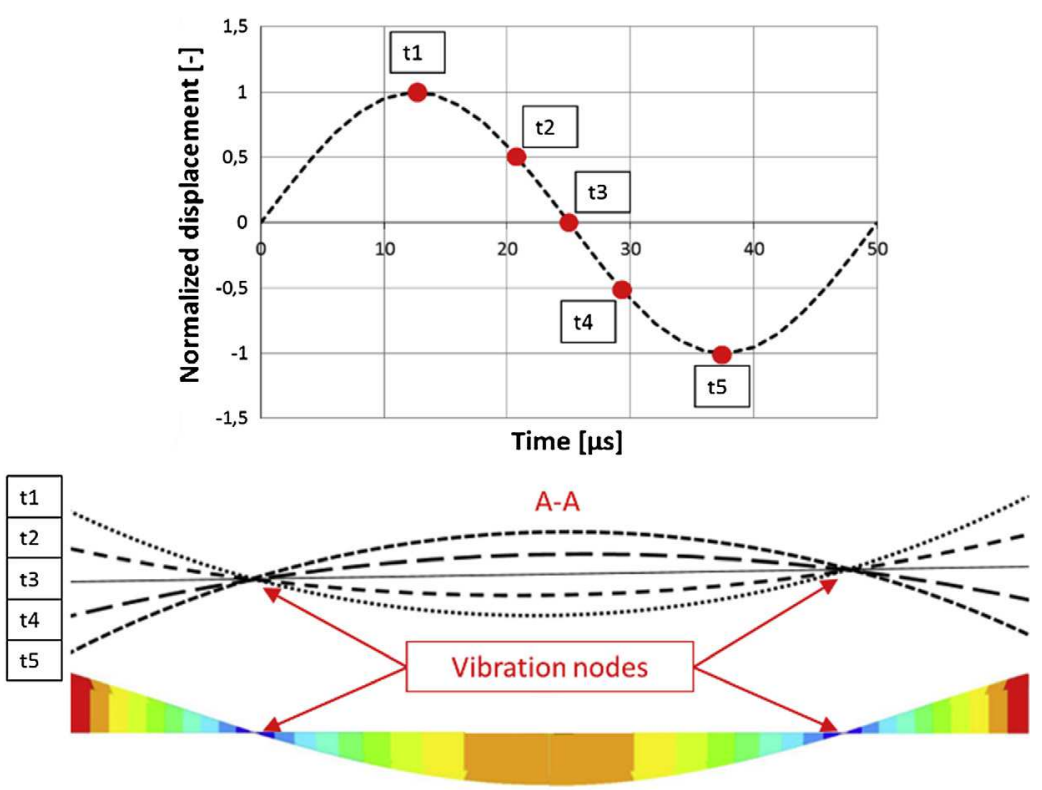

(b)

Fig. 2. (a) Specimen geometry for a first natural mode at $20 \mathrm{kHz}$ and (b) cut view of the associated deformed shape at 5 given moments and displacement by $10 \%$ intervals.

enough from $20 \mathrm{kHz}$ (and multiples) to avoid the risk of parasite vibrations. In practice we recommend at least $\pm 2 \mathrm{kHz}$ from $20 \mathrm{kHz}$. For a given stress state at the center of the lower face, contact forces rapidly increase with thickness. On the other hand, since the hemispherical indenter is located at the center of the upper face, the stress state at the center of the lower face (where cracks will initiate) might be disturbed by the loading if the disc is too thin. For the application described in the next section, a compromise has been found by fixing the thickness equal to $6 \mathrm{~mm}$. The radius of the circular ring in Fig. 1a is given by the location of the vibration nodes on the specimen (Fig. 2b). This choice minimizes the relative displacement between the specimen and the frame, then the frictional-induced heating. Please note that dimensions in Fig. 2a were determined for the cast Al-Si alloy tested in the next section. These dimensions remain valid for other Al-Si alloys with slightly different density and dynamic modulus, but we recommend to perform the modal analysis again for every new material.

\subsection{Associated stress state}

\subsubsection{Experimental analysis of the stress state}

Theoretically, disc bending generates an equi-biaxial proportional stress state at the center of the specimen's lower face, and the stress level is proportional to the center's displacement [15]. Three calibration specimens were instrumented with strain gauge rosettes glued in the center of the lower face. Tests were performed for different amplitudes of the displacement, with a static load assuring a positive load ratio. Three centering pins are used to keep the specimen centered on the frame ring while the static load is applied. In order to avoid friction during cyclic loading, they are removed before applying the sinusoidal displacement. After measuring strain amplitudes using both a wide band conditioning device (Vishay 2210) and a high speed data recorder, stresses amplitudes were computed assuming an isotropic linear elastic behavior of the material (because of testing conditions in the VHCF regime). Since the results are almost proportional to the displacement, Table 1 summarizes the results on 3 specimens for a given $10 \mu \mathrm{m}$ amplitude of displacement at the center of the specimen. Considering the uncertainties related to the experimental mea-
Table 1

Stresses at the center of the lower face of the specimen for an amplitude of displacement of $10 \mu \mathrm{m}$.

\begin{tabular}{llll}
\hline $\begin{array}{l}\text { Specimen } \\
\text { number }\end{array}$ & $\begin{array}{l}\text { 1st principal } \\
\text { stress amplitude } \\
(\mathrm{MPa})\end{array}$ & $\begin{array}{l}\text { 2nd principal } \\
\text { stress amplitude } \\
(\mathrm{MPa})\end{array}$ & $\begin{array}{l}\text { Von Mises equivalent } \\
\text { stress amplitude } \\
(\mathrm{MPa})\end{array}$ \\
\hline 1 & 27.8 & 26.2 & 27.0 \\
2 & 26.9 & 26.6 & 26.8 \\
3 & 28.2 & 26.5 & 27.4 \\
\hline
\end{tabular}

surements (location of the strain gauges, gauge factors, etc.), stress state can be considered equi-biaxial.

\subsubsection{Reproducibility of the stress state}

During a $10^{9}$ cycles run-out test, the static force applied by the electro-mechanical testing machine is almost constant $( \pm 0.2 \%$; Fig. 3a). The resonance frequency of the whole device slightly decreases then stabilizes ( $-0.2 \%$; Fig. $3 \mathrm{~b}$ ), possibly due to the specimen's heating or to an evolution of the boundary conditions (penetration of the hemispherical indenter; compression of the PTFE layer between the specimen and the circular ring, see Section 4.1). The displacement amplitude can be monitored but not recorded. However, the accuracy on displacement amplitude should be better than the accuracy on strain amplitudes measured using strain gauges under ultrasonic loading, which is lower than $2 \%(10 \mu \mathrm{m} /$ $\mathrm{m}$ ). We can conclude that the loading applied to the specimen is stable, with a good reproducibility and a good accuracy.

\section{Application to a cast Al-Si alloy}

This ultrasonic biaxial fatigue testing device has been tested and validated on a cast aluminum alloy used to produce cylinder heads and previously investigated by Koutiri et al. [13,15]. Since cast materials may contain casting defects (porosities, shrinkages, etc.), and because cylinder heads are submitted to high hydrostatic pressure loadings during a very high number of loading cycles, a safe fatigue design requires to determine the fatigue strength of this material under a similar stress state in the gigacycle regime. 


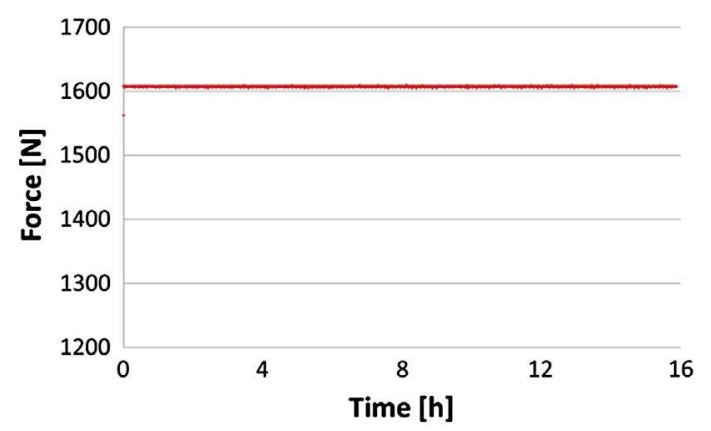

(a)

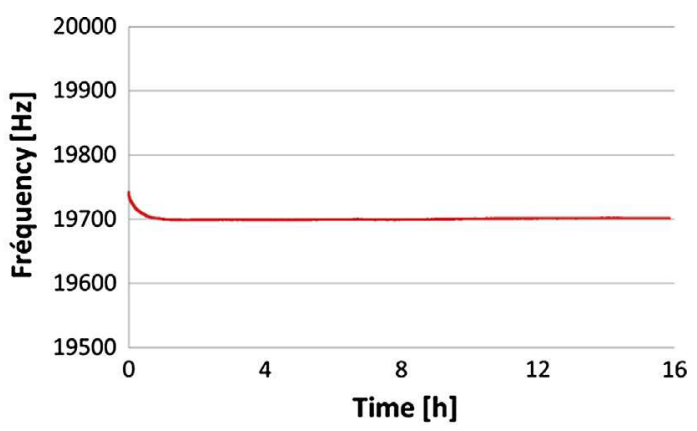

(b)

Fig. 3. (a) Static force and (b) frequency evolution during a $10^{9}$ cycles run-out test.

Nevertheless, the objective here is only to validate the new testing device.

\subsection{Material and specimen}

The material is the cast AlSi7Cu05Mg03 T7. Its conventional yield stress is $250 \mathrm{MPa}[13,15]$. The specimen's geometry and microstructure are illustrated in Figs. 2a and 4a respectively. Specimens were machined from cast cylinder heads. In order to get enough material volume, cores were diminished prior to casting (Fig. 4b). This allows for microstructure parameters similar to real components (in terms of dendrite arm spacing or DAS, porosities, and hardness), even if Koutiri [13] showed that diminishing casting cores leads to larger porosities. The circular ring has a $34 \mathrm{~mm}$ diameter. In order to reduce friction, a $0.4 \mathrm{~mm}$ thick PTFE layer is fixed on the ring using polyimide tape.

\subsection{Testing conditions and fatigue test results}

Fatigue tests were performed in air, at room temperature, with $\mathrm{R}=0.1$ load ratio. Cyclic loading is stopped after $10^{9}$ cycles, or when the loading frequency drops down to $19,500 \mathrm{~Hz}$ due to fatigue crack initiation and propagation. Both static load and sinusoidal displacement levels were determined using calibration specimens following the procedure previously described in Section 3.3.1.
Since ultrasonic loading may generate self-heating, specimen cooling is necessary. To cool the specimen, dry compressed air flow was orientated with an air gun towards the specimen upper face (Figs. $1 \mathrm{~b}$ and $5 \mathrm{a}$ ). In order to quantify self-heating, surface temperature has been measured using an infrared camera (FLIR SC 7000) during some tests for which the specimen was previously mat black painted for ensuring a high emissivity (Fig. 5a). It was not possible to place the camera perpendicular to a specimen surface, because both upper and lower faces of the specimen are obstructed (by the ultrasonic loading device and by the frame, Fig. 1b). However, for measuring relative temperature variation, $\Delta \mathrm{T}$, compared with the initial room temperature, such configuration can be used. It was not possible either to observe the lower face of the specimen, where self-heating associated with cyclic loading should be the larger. But according to the high thermal conductivity, temperature is sufficiently homogeneous. Indeed, although the compressed air flow is directed towards the specimen upper face, the area labelled 1 in Fig. 5 a was only $2-3^{\circ}$ warmer than the one labelled 2.

Temperature was averaged on the areas labelled 1 and 2 in Fig. 5a. After $2.5 \times 10^{6}$ cycles, the mean temperature increase compared to room temperature - almost stabilizes at $42-52$ $57^{\circ} \mathrm{C}$ for maximal stresses equal to $130-140-150 \mathrm{MPa}$ respectively. Self-heating is more pronounced than during tensioncompression ultrasonic testing due to the much larger specimen volume. However, the precipitation strengthened Al-Si alloy tested in this study is in T7 condition, which involves a final heat treat-

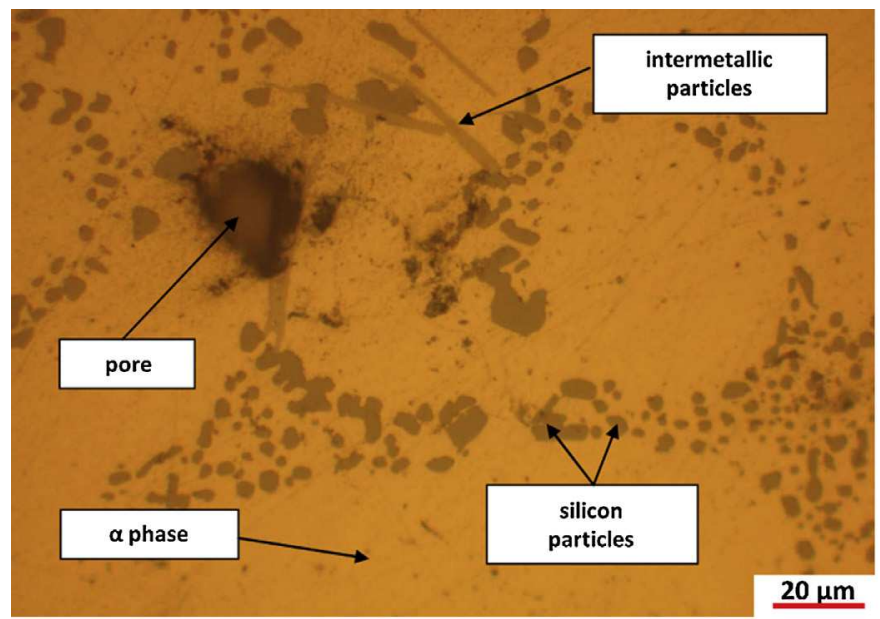

(a)

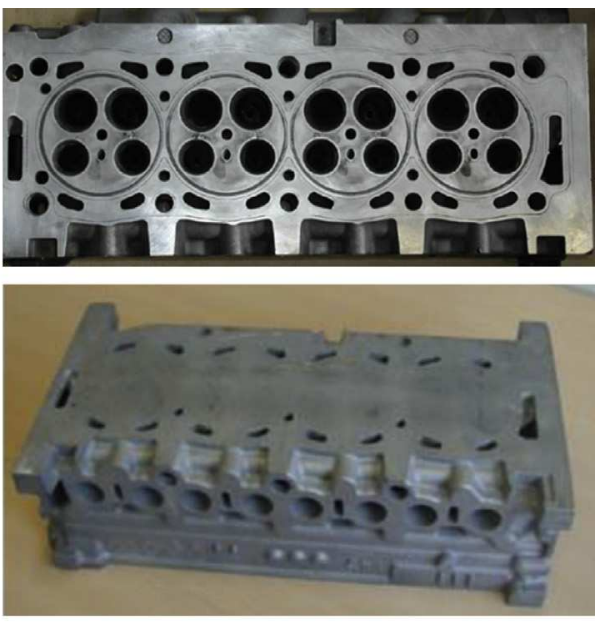

(b)

Fig. 4. (a) Microstructure of the AlSi7Cu05Mg03 T7 according to Koutiri [13] and (b) cylinder heads without or with diminished casting cores. 


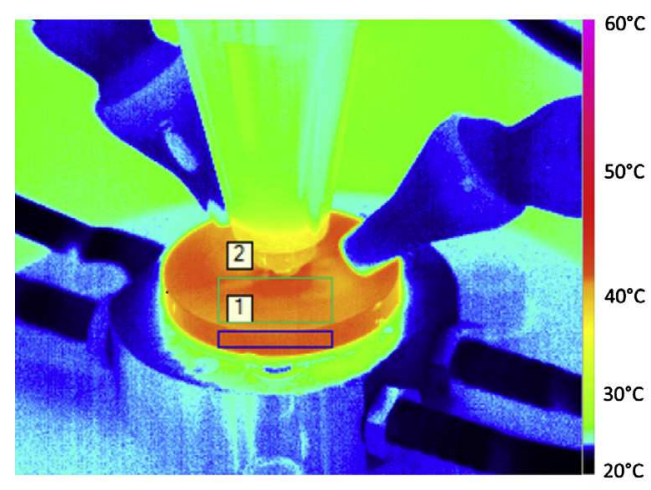

(a)

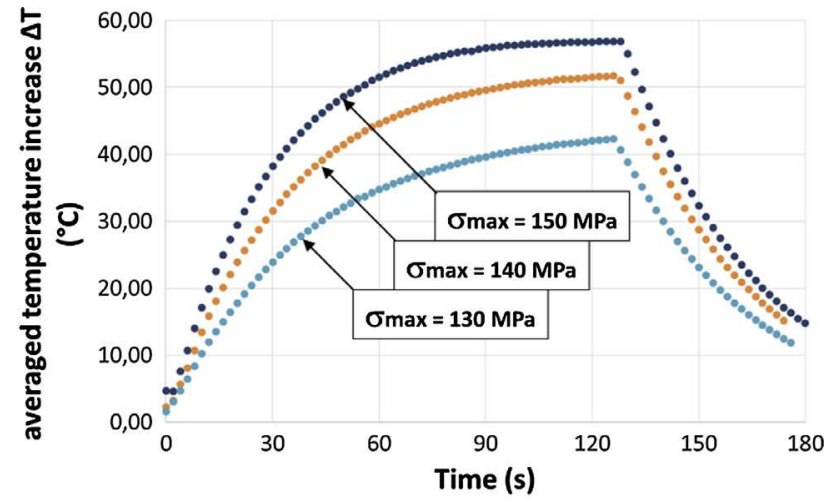

(b)

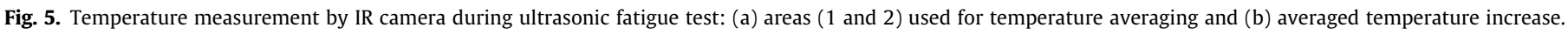

ment at $200{ }^{\circ} \mathrm{C}$ during $5 \mathrm{~h}$. For a maximum stress equal to $140 \mathrm{MPa}$ (leading to the gigacycle regime, see Fig. 6), the specimen temperature reaches $75^{\circ} \mathrm{C}$ during $14 \mathrm{~h}$, the duration of a test up to $1 \mathrm{E} 9$ cycles at $20 \mathrm{kHz}$. Such temperature should be low enough to be neglected compared to the final heat treatment.

The first fatigue test results are illustrated in Fig. 6. Additional results obtained in HCF regime for the same material and similar stress state but at $20 \mathrm{~Hz}[13,15]$ are also presented for comparison purpose.

\subsection{Discussion}

For maximum stress levels equal or lower than $140 \mathrm{MPa}$, the first results obtained with the new ultrasonic biaxial testing device show a longer fatigue life than the results by Koutiri et al. $[13,15]$. The number of tested specimens at $20 \mathrm{~Hz}$ and $20 \mathrm{kHz}$ is too low for being statistically representative. Nevertheless, in addition to the temperature effect discussed in the previous section, and to a possible frequency effect, various sources of discrepancy were identified on these preliminary results. It has to be pointed out that we used a hemispherical indenter whereas Koutiri et al. used a ring indenter generating a constant stress state in a $10 \mathrm{~mm}$ diameter disc of the lower face. Consequently the highly stressed volume is larger on the tests at $20 \mathrm{~Hz}$ by Koutiri et al. than in our case at $20 \mathrm{kHz}$. The fatigue life is thus a little bit shorter at $20 \mathrm{~Hz}$ because the probability to find a critical defect is higher.

In order to estimate the highly stressed volume of material (submitted to $90 \%$ of the maximum normal stress), disc bending was simulated using a commercial FEA software, assuming an isotropic and homogeneous defect-free material with a linear elastic behavior and no sliding between the frame ring and the specimen lower face. Fig. 7 shows the radial $\left(\sigma_{\mathrm{rr}}\right)$ and circumferential $\left(\sigma_{\theta \theta}\right)$ stresses in the median section of the disc. Zones with a uniform grey color are under negative stress. Color bands show positive stress values by $5 \%$ intervals. The maximum values are identical and located at the center of the lower face (where the stress state is then equi-biaxial), but the two profiles differ. The radial $\left(\sigma_{\mathrm{rr}}\right)$ and circumferential $\left(\sigma_{\theta \theta}\right)$ stresses are $10 \%$ lower on a $3 \mathrm{~mm}$ and $4 \mathrm{~mm}$ diameter disc, respectively. Along the specimen thickness, the two stresses decrease by $10 \%$ after $0.25 \mathrm{~mm}$. This value is related to the disc thickness $(6 \mathrm{~mm})$ and should then be slightly larger in this study than in the one by Koutiri et al., who used $5 \mathrm{~mm}$ thick discs. Even so, the highly stressed volume is smaller in our case. This highly stressed volume difference seems to counterbalance the dif-

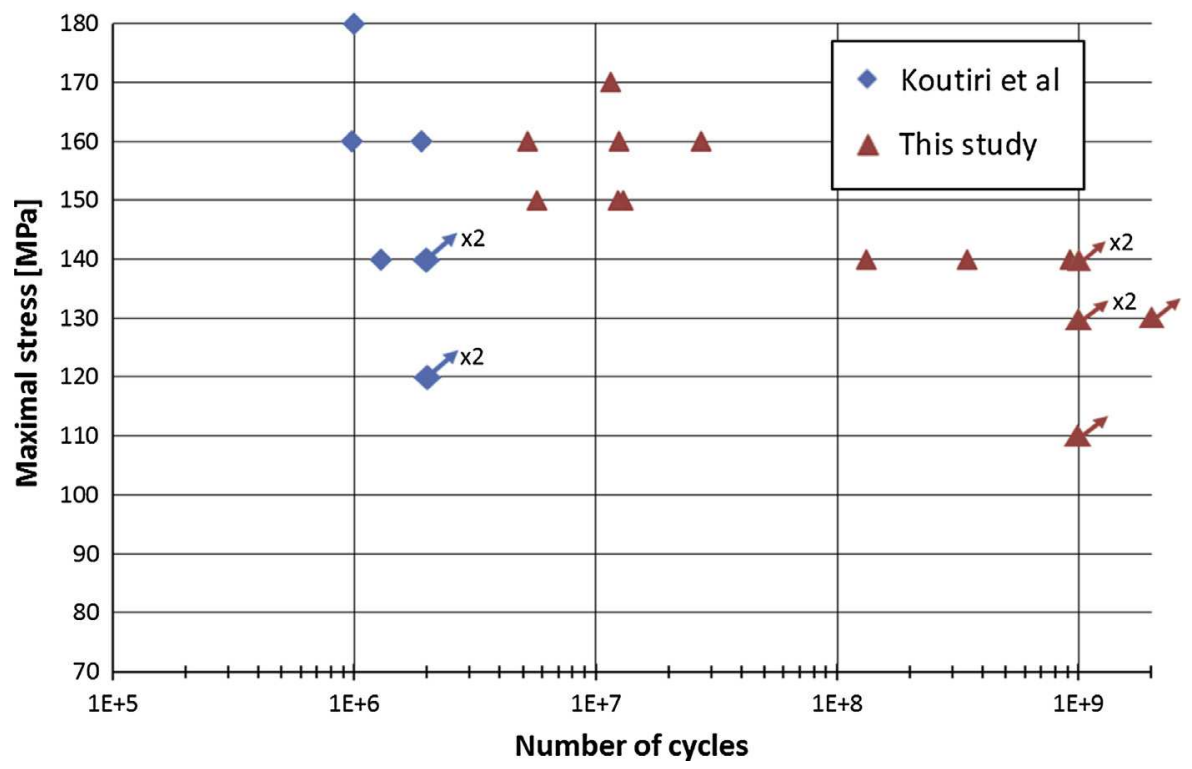

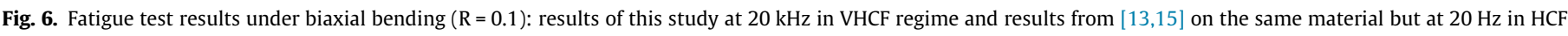
regime. 


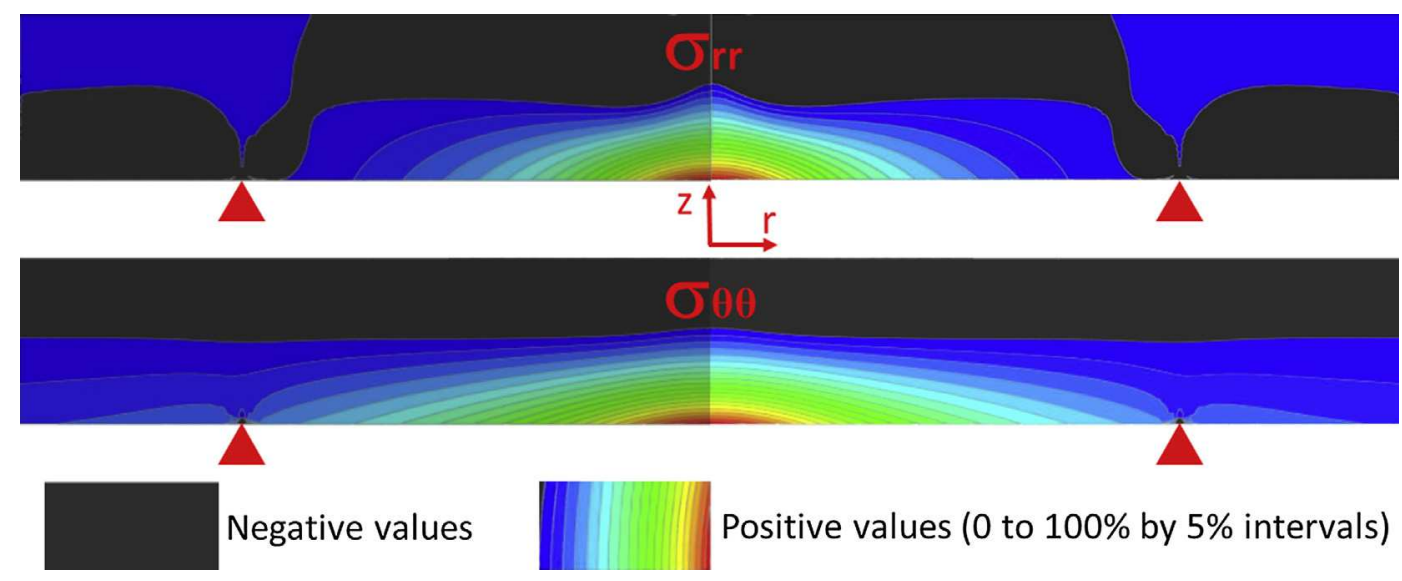

Fig. 7. Radial $\left(\sigma_{\mathrm{rr}}\right)$ and circumferential $\left(\sigma_{\theta \theta}\right)$ stresses in the median section of a disc.

ference in fatigue life compared to the Koutiri's results, leading to similar median fatigue strengths.

In term of stress amplitude, the median fatigue strength at $10^{9}$ cycles is close to $63 \mathrm{MPa}$ (corresponding to a maximal stress equal to $140 \mathrm{MPa}$ ). Fig. 8a illustrates, in a Dang-Van diagram [16], both the experimental median fatigue strengths at $2 \times 10^{6}$ cycles obtained by Koutiri [13] on smooth specimens made in the same cast $\mathrm{Al}$ alloy and the threshold line at $2 \times 10^{6}$ cycles identified from torsion $(\mathrm{R}=-1)$ and tension $(\mathrm{R}=0.1)$ fatigue test data on smooth specimens tested at classic low frequency. Furthermore, the loading paths corresponding to existing ultrasonic fatigue testing machines are shown: torsion $(R=-1)$, tension $(R=-1)$, tension or 3 points bending $(R>0)$. The loading path corresponding to the specimens tested at the stress level corresponding to $10^{9}$ cycles with the new ultrasonic biaxial testing device presented here is illustrated. Even if the results of this study are preliminary data only, it is clear that these results allow us to question the assessment of the fatigue strength given by the Dang-Van criterion for high hydrostatic stress states even at $2 \times 10^{6}$ cycles. Indeed, our experimental fatigue strength at $10^{9}$ cycles under biaxial stress state is above this threshold line (Fig. 8a). The same conclusion is valid for the Crossland criterion too [17], as shown in Fig. 8b. Furthermore one has to point out that additional studies have to be carried out to propose an efficient criterion for multiaxial fatigue strength assessment in VHCF regime.

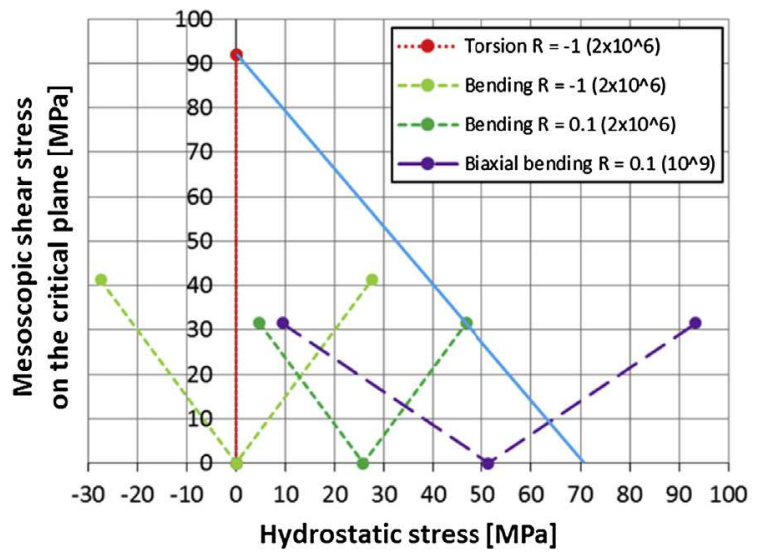

(a)
For maximum stress levels equal or greater than $150 \mathrm{MPa}$ (Fig. 6), another difference between experimental procedures must be accounted for: the stop criterion. Indeed, the test results presented in this paper were stopped when the resonance frequency decreased from about $19,900 \mathrm{~Hz}$ to $19,500 \mathrm{~Hz}$. Such loading frequency drop is due to a rigidity loss associated to a large macroscopic fatigue crack propagation. Indeed, macroscopic cracks are either unique or branched but always extended almost to the frame ring when the test stops (Fig. 9). Their length at the specimen surface is thus around $17 \mathrm{~mm}$. Additional investigations are needed to quantify the number of cycles associated with this propagation, but first observations indicate it might exceed $10^{7}$ cycles. However, one can note that $10^{7}$ cycles represent $1 \%$ of $10^{9}$ cycles only. The stop criterion used by Koutiri et al. leads to $6 \mathrm{~mm}$ long macroscopic fatigue cracks, and then to a shorter fatigue life.

\subsection{Fractographic analyses}

After ultrasonic fatigue testing, the cracked specimens are not broken in two parts (Fig. 9a). For an easy observation of the fatigue crack path, each specimen was fractured under quasi-static monotonic loading. To do that, the disc was placed between a circular ring and a hemispherical indenter (like on the ultrasonic testing machine, but with a larger diameter) and loaded in compression under displacement control using an electromechanical classic testing machine. When macroscopic fatigue crack is unique

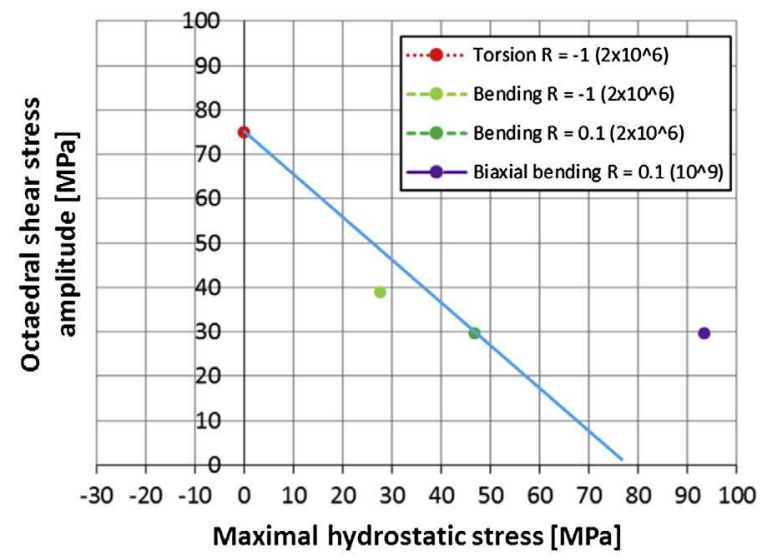

(b)

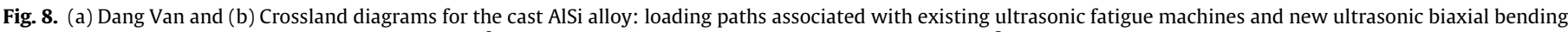
device; and comparison of experimental result at $10^{9}$ cycles under biaxial bending with threshold at $2 \times 10^{6}$ cycles. 


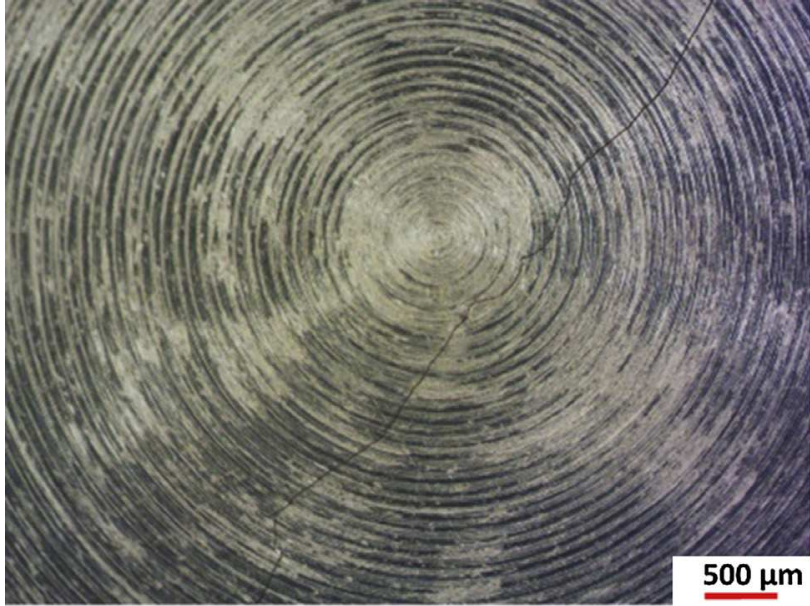

(a)

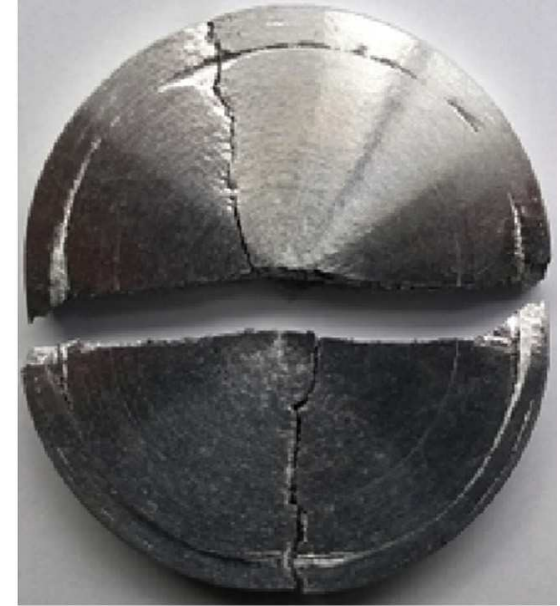

(b)

Fig. 9. Macroscopic fatigue crack on the lower face of the specimen (a) after testing and (b) after breaking it under monotonic quasi-static loading.

(Fig. 9a), quasi-static loading generates two new cracks, and specimen is finally broken in four parts (Fig. 9b).

Koutiri [13] observed multiple initiation sites on the fracture surfaces of disc specimens tested in bending in HCF regime, unlike specimens tested under uniaxial loading. We made the same observation in VHCF regime: at least 6 initiation sites are visible on the fracture surfaces of the specimen presented in Fig. 10. However, we could not determine in which order crack initiations occurred. As it can be seen in Fig. 9, the surface quality of the specimens used for these preliminary tests was poor. Additional tests on polished specimens are required to clarify whether multiple crack initiation is due to the surface quality or to the multiaxial stress state.

Koutiri et al. $[13,14]$ also showed that the tested cast aluminum alloy contains relatively small $(\sim 100 \mu \mathrm{m})$ casting defects (shrinkages, pores), and that most of the fatigue cracks initiate on these casting defects. Indeed, such defects are responsible for fatigue crack initiation both in HCF and in VHCF regime. This can be seen in Fig. 11 where two fatigue crack initiations are very close to shrinkages with sizes close to $100 \mu \mathrm{m}$.

Finally, Koutiri et al. [13,14] and Le et al. [18] also observed some crack initiations on eutectic silicon particles, oxide films and iron based intermetallic particles. Fig. 12 illustrates a crack initiation that occurred without any casting defect, and authors suspect crack initiation on $\mathrm{Si}$ or iron based intermetallic particles, nevertheless exact localization of the crack initiation can't be precisely achieved.

\section{Conclusion and prospects}

A new ultrasonic fatigue testing device generating a biaxial proportional stress state with a positive loading ratio has been designed and successfully tested. For validating this equipment, VHCF tests were performed on a cast aluminum alloy already tested in the literature in HCF regime under a similar stress state. The preliminary results are consistent with data from the literature but some sources of discrepancy were identified and should be addressed to correctly determine the fatigue strength of materials under high hydrostatic stress in the gigacycle regime. Self-heating is more pronounced than during tension-compression ultrasonic testing. In future work the stop criterion should be improved to detect smaller cracks, as well as the surface quality of the specimens. Preliminary results show that both Dang-Van and Crossland criteria do not give good assessment of the VHCF strength under high hydrostatic stress. Fracture mechanisms are also consistent with the literature for the tested cast aluminum alloy: multiple crack initiations occurred, either on casting defects (pores or shrinkages), or without any casting defect. Additional work has to be done on specimens with a better surface quality to identify the crack initiation area, as two competing parameters play a role:

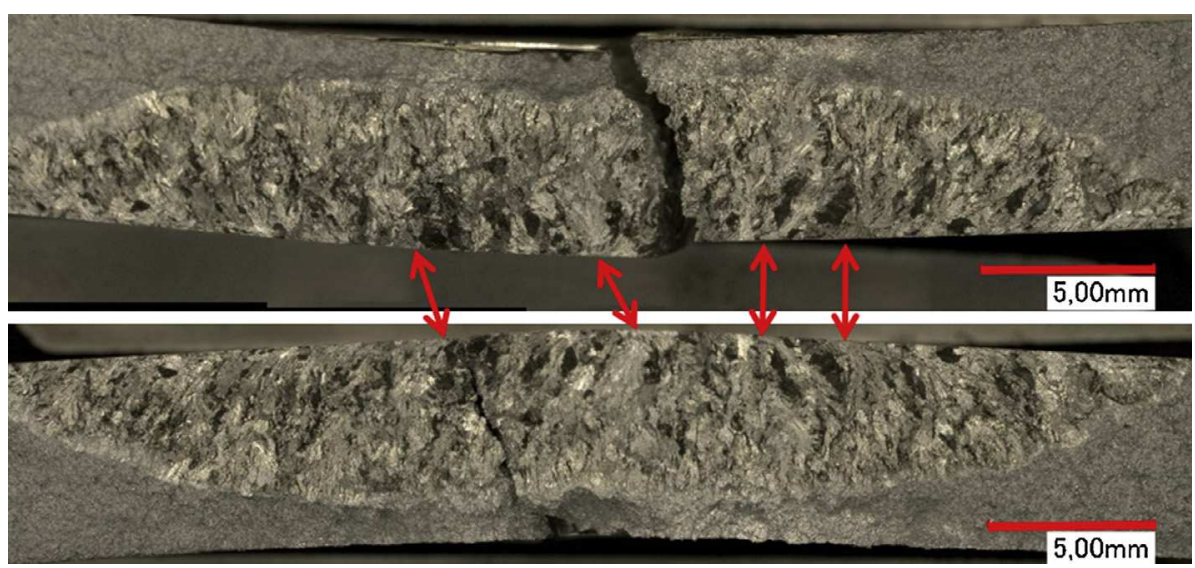

Fig. 10. Macroscopic fatigue fracture surface ( $\sigma \mathrm{max}=140 \mathrm{MPa} ; \mathrm{R}=0.1 ; \mathrm{N}=3.46 \times 10^{8}$ cycles): upper part and lower part of the fractured specimen shown in Fig. $9 \mathrm{~b}$. 

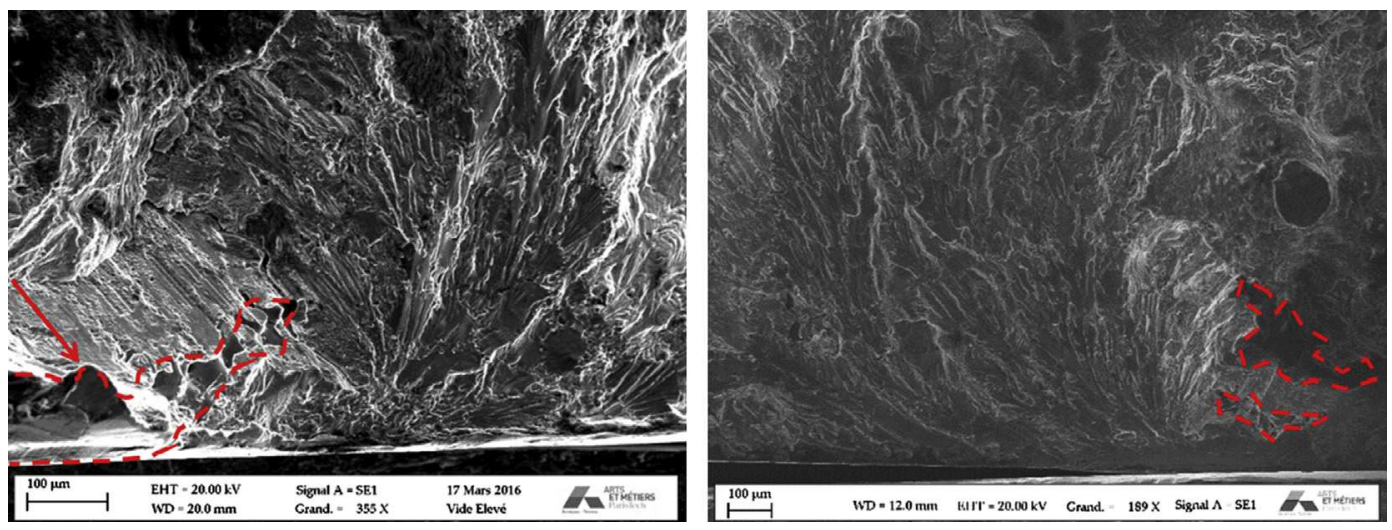

Fig. 11. Two fatigue crack initiations close to shrinkages ( $\sigma \max =160 \mathrm{MPa} ; \mathrm{R}=0.1 ; \mathrm{N}=2.7 \times 10^{8}$ cycles).

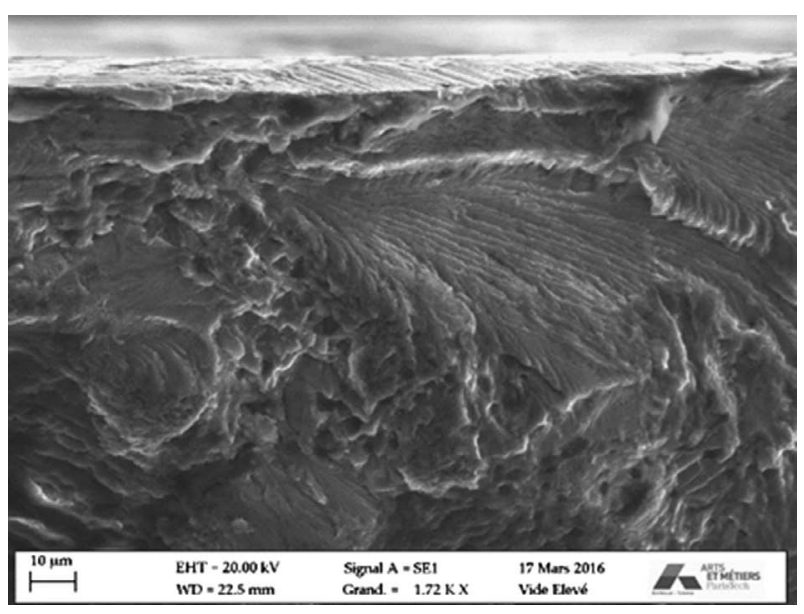

Fig. 12. Fatigue crack initiation without any casting defect $(\sigma \max =140 \mathrm{MPa}$; $\mathrm{R}=0.1 ; \mathrm{N}=1.3 \times 10^{8}$ cycles).

the biaxial stress state which is maximal on the surface, and the presence of subsurface defects in cast materials.

\section{References}

[1] Bathias C, Paris PC. Gigacycle fatigue in mechanical practice. New York, USA: Marcel Dekker Publisher Co.; 2005.

[2] Palin-Luc T, Perez-Mora R, Bathias C, Dominguez G, Paris PC, Arana J-L. Fatigue crack initiation and growth on a steel in the very high cycle regime with sea water corrosion. Eng Fract Mech 2010;77:1953-62.
[3] Perez-Mora R, Palin-Luc T, Bathias C, Paris PC. Very high cycle fatigue of a high strength steel under sea water corrosion: a strong corrosion and mechanical damage coupling. Int J Fatigue 2015;74:156-65.

[4] Mason WP. Piezoelectric crystals and their application in ultrasonics. New York: Van Nostrand; 1956. p. 161.

[5] Bathias C. Piezoelectric fatigue testing machines and devices. Int J Fatigue 2006;28:1438-45.

[6] Mason WP. Ultrasonic fatigue. In: Well JM, Buck Roth O.L.D., Tien J.K., editors. In proceed. 1st Int. conf fatigue and corrosion fatigue up to ultrasonic frequencies, (PA) USA: The Metallurgical Society of AIME; 1982. p. 87-102.

[7] Stanzl-Tschegg SE, Mayer HR, Tschegg EK. High frequency method for torsion fatigue testing. Ultrasonics 1993;31:275-80.

[8] Mayer H. Ultrasonic torsion and tension-compression fatigue testing: measuring principles and investigations on 2024-T351 aluminium alloy. Int J Fatigue 2006;28:1446-55.

[9] Nikitin A, Bathias C, Palin-Luc T. A new piezoelectric fatigue testing machine in pure torsion for ultrasonic gigacycle fatigue tests: application to forged and extruded titanium alloys. Fat Frac Eng Mater Struct 2015;38:1294-304.

[10] Wagner D, Cavalieri FJ, Bathias C, Ranc N. Ultrasonic fatigue tests at high temperature on an austenitic steel. Propul Power Res 2012;1:29-35.

[11] Vieira M, De Freitas M, Reis L, Ribeiro AMR, Da Fonte M. Development of a very high cycle fatigue (VHCF) multiaxial testing device. Frattura ed Integrita Strutturale 2016;37:131-7.

[12] Blanc M, Osmond P, Palin-Luc T, Bathias C. French patent N FR1357198; 2013.

[13] Koutiri I. Effet des fortes contraintes hydrostatiques sur la tenue en fatigue des matériaux métalliques. PhD thesis ENSAM N 2011-ENAM-0015; 2011.

[14] Koutiri I, Bellett D, Morel F, Augustins L, Adrien J. High cycle fatigue damage mechanisms in cast aluminium subject to complex loads. Int J Fatigue 2013;47:44-57.

[15] Koutiri I, Morel F, Bellett D, Augustins L. Effect of high hydrostatic stress on the fatigue behavior of metallic materials. ICF-12 2009;5:3694-703.

[16] Dang-Van K, Cailletaud G, Flavenot JF, Douaron L, Lieurade HP. In: Brown M, Miller K, editors. Biaxial and multiaxial fatigue. Sheffield: ESIS; 1989. p. 459-78.

[17] Crossland. In: Int. Conf. on Fat. of Metals (London, 1959), Inst. of. Mech. Eng. p. 138-49.

[18] Le V-D, Morel F, Bellett D, Saintier N, Osmond P. Multiaxial high cycle fatigue damage mechanisms associated with the different microstructural heterogeneities of cast aluminium alloys. Mater Sci Eng A 2016;649:426-40. 